\title{
Biventricular vortex ring formation corresponds to regions of highest intraventricular viscous energy loss in a Fontan patient: analysis by 4D Flow MRI
}

\author{
Vivian P. Kamphuis ${ }^{1,2} \cdot$ Arno A. W. Roest $^{1} \cdot$ Jos J. M. Westenberg $^{3}$ • \\ Mohammed S. M. Elbaz ${ }^{3}$
}

Received: 13 September 2017 / Accepted: 21 September 2017 / Published online: 30 September 2017

(c) The Author(s) 2017. This article is an open access publication

\section{Image focus}

An adult patient with a Fontan circulation because of a complete atrioventricular septal defect (Fig. 1a) and a double outlet right ventricle with pulmonary stenosis, underwent a magnetic resonance imaging (MRI) scan including wholeheart four-dimensional (4D) Flow MRI as part of routine follow-up. 4D Flow MRI was used to assess intracardiac vortical flow patterns and in vivo viscous energy loss (EL)the kinetic energy that is irreversibly lost due to viscosityinduced frictional forces-during diastole around peak early filling [1].

4D Flow MRI-derived streamline visualization showed a complex three-dimensional (3D) inflow pattern from the common atrioventricular valve with the formation of vortical flow around the ventricular part of the septal defect
(Fig. 1b). Mathematical identification of vortex core structures from 4D Flow MRI [2] showed a large 3D ring-like vortex formation filling the common biventricular region at the level of the ventricular septal defect, with protrusion in both ventricles (Fig. 1c). To assess the regions of highest EL in this patient, a map of EL inside the ventricle was made in the cross-sectional four-chamber view (Fig. 1d). In Fig. 1e, regions of the identified $3 \mathrm{D}$ vortex structure associate with the highest EL levels in the EL map. These high EL levels anatomically correspond to the region of the ventricular septal defect and part of the remaining septum.

Knowledge on the consequences of intracardiac deformations on hemodynamic vortex formation and viscous energy loss might be useful in unraveling the pathophysiological mechanisms leading to circulatory failure, one of the main causes of morbidity and mortality in Fontan patients.
Vivian P. Kamphuis

v.p.kamphuis@lumc.nl

1 Department of Pediatrics, Division of Pediatric Cardiology, Leiden University Medical Center, Leiden, The Netherlands

2 Netherlands Heart Institute, Utrecht, The Netherlands

3 Department of Radiology, Leiden University Medical Center, Leiden, The Netherlands 

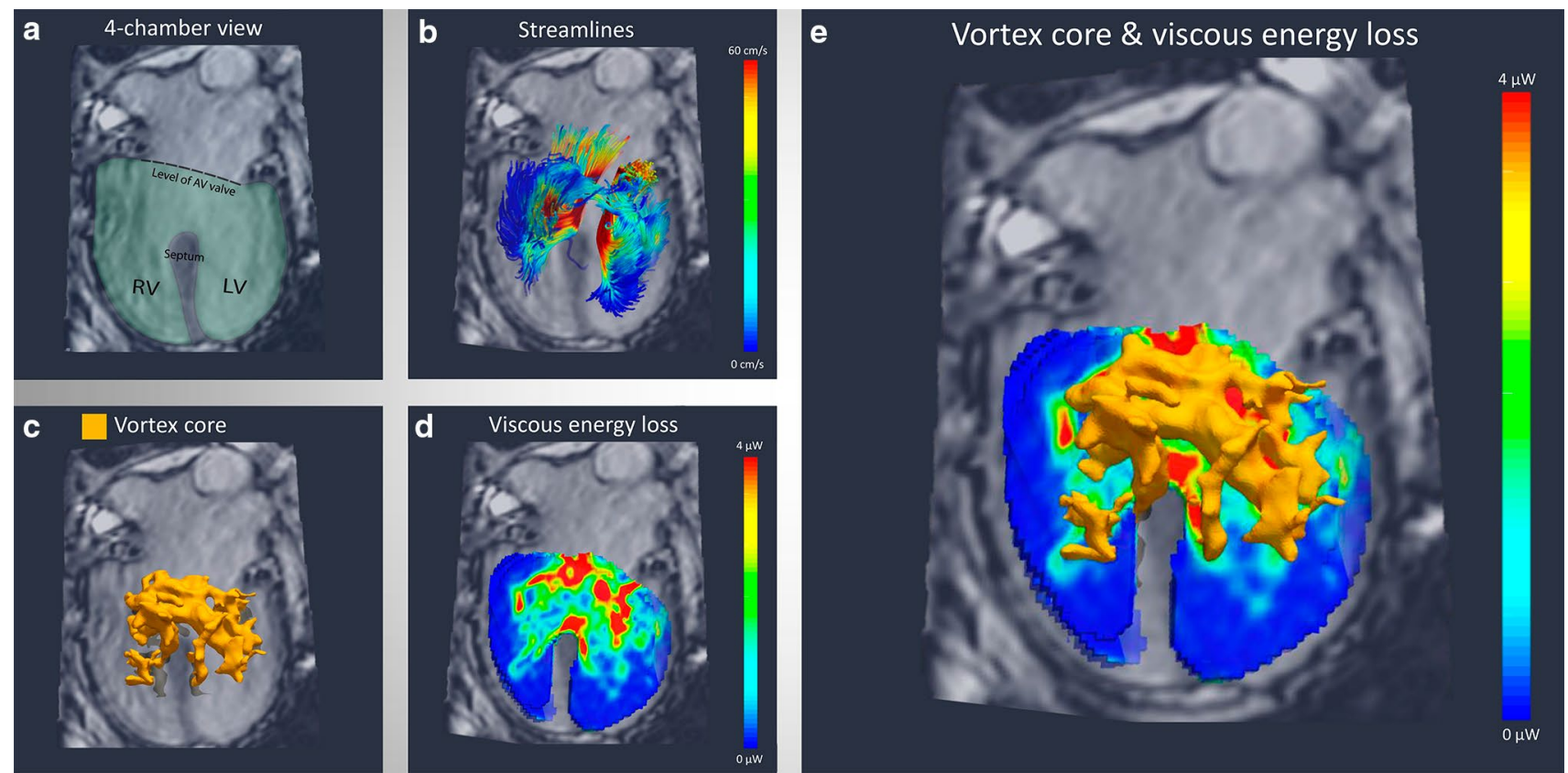

Fig. 1 Vortical flow and viscous energy loss in a patient with a Fontan circulation

Funding V.P. Kamphuis is financially supported by a Grant from the Dutch Heart Foundation (Grant No. 2013T091). J.J.M. Westenberg is financially supported by a Grant of ZonMw (Project Number 104003001).

\section{Compliance with ethical standards}

\section{Conflict of interest None.}

Open Access This article is distributed under the terms of the Creative Commons Attribution 4.0 International License (http://creativecommons.org/licenses/by/4.0/), which permits unrestricted use, distribution, and reproduction in any medium, provided you give appropriate credit to the original author(s) and the source, provide a link to the Creative Commons license, and indicate if changes were made.

\section{References}

1. Elbaz MS, van der Geest RJ, Calkoen EE, de Roos A, Lelieveldt BP, Roest AA, Westenberg JJ (2016) Assessment of viscous energy loss and the association with three-dimensional vortex ring formation in left ventricular inflow: in vivo evaluation using four-dimensional flow MRI. Magn Reson Med. doi:10.1002/ mrm. 26129

2. Elbaz MS, Calkoen EE, Westenberg JJ, Lelieveldt BP, Roest AA, van der Geest RJ (2014) Vortex flow during early and late left ventricular filling in normal subjects: quantitative characterization using retrospectively-gated 4D flow cardiovascular magnetic resonance and three-dimensional vortex core analysis. J Cardiovasc Magn Reson 16:78. doi:10.1186/s12968-014-0078-9 